Pathologe 2013 $34: 177$

DOI 10.1007s00292-013-1757-2

๑) Springer-Verlag Berlin Heidelberg 2013

\section{SGPath SSPath}

Société Suisse de Pathologie

Schweizerische Gesellschaft für Pathologie

Swiss Society of Pathology

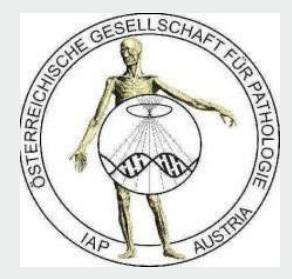

Österreichische Gesellschaft für Pathologie

Sekretariat der ÖGP Institut für Pathologie Auenbruggerplatz 25 A-8036 Graz Tel. +43(0) 55223033402 Tel. +43(0) 3163804417 Fax +43(0) 31638513432 office@pathology.at www.pathology.at
Schweizerische Gesellschaft für Pathologie

Dr. P. A. Diener, Sekretariat Institut für Pathologie Kantonsspital St. Gallen Rorschacherstrasse 95 CH-9007 St. Gallen Tel. +41(0) 714942105 Fax +41(0) 714942894 P. A. Diener p.a.diener@kssg.ch oder info@sgpath.ch

\title{
Joint Annual Meeting of the Swiss and Austrian Societies of Pathology (SGPath/SSPath and ÖGP)
}

\section{Dear colleagues!}

The next

Joint Annual Meeting of the Swiss and Austrian Societies of Pathology (SGPath/SSPath and ÖGP)

will take place

November 7-9, 2013

at the

TRAFO Baden

5404 Baden, Switzerland

www.trafobaden.ch

\section{Contact:}

Prof. Dr. med. Gad Singer President of the Meeting Institut für Pathologie

Kantonsspital Baden AG

$\mathrm{CH}-5404$ Baden

Switzerland

Phone ++41-56-486 3902

Fax ++41-56-486 3919

Mail to: gad.singer@ksb.ch

Key topics:

Update on Gastrointestinal Surgical and Molecular Pathology

Robert Genta, USA

Cord Langner, Austria

Heinz-Josef Lenz, USA

Alessandro Lugli, Switzerland

Elisabeth Montgomery, USA

Iris Nagdegaal, The Netherlands

Felix Offner, Austria

Robert Riddell, Canada

Neil Shepherd, UK
Surgical and Molecular Pathology of Mesenchymal Tumors of the Uterus and Ovary

Glenn McGluggage, UK

Sigurd Lax, Austria

Esther Oliva, USA

Jaime Prat, Spain

Surgical and Molecular Pathology of Mesenchymal Lesions and Carcinoma of the Prostate

Lukas Bubendorf, Switzerland Lars Egevad, Sweden Jonathan Epstein, USA Sven Perner, Germany Hermann Rogatsch, Austria

Workshop: Endocrine Pathology Paul Komminoth, Switzerland Aurel Perren, Switzerland

Slide Seminar Mesenchymal Tumors of the Urogenital and Gastrointestinal Tracts Speakers from the main presentations

Detailed program will follow. Please save the dates! 